\title{
Hansen's Disease: An Imitator of Cutaneous Sarcoidosis
}

\author{
Katsuya Chinen $^{1,2}$, Kazuhiko Hirano ${ }^{1}$ and Yasunori Fujioka ${ }^{1}$
}

Key words: Hansen's disease, epithelioid cell granuloma, acid-fast bacilli, modified Ziehl-Neelsen stain (Fite method)

(Intern Med 50: 2257-2258, 2011)

(DOI: 10.2169/internalmedicine.50.5642)

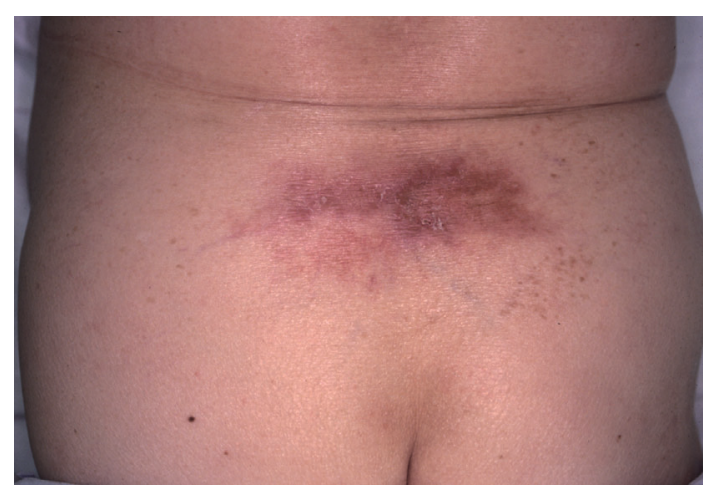

Picture 1.

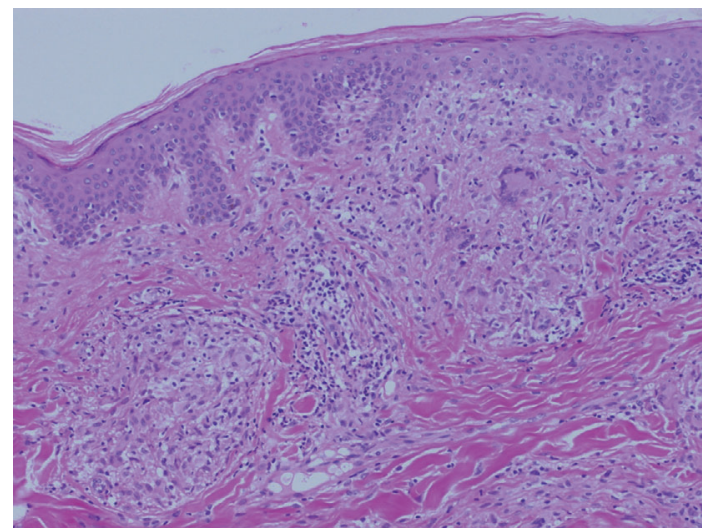

Picture 2.

An 80-year-old Japanese woman, who had past history of hypertension, diabetes mellitus, and unruptured abdominal aorta aneurysm, felt cutaneous induration in her lower back 1 year earlier. She noticed skin eruption in the same region and visited a hospital. Physical examination revealed illdemarcated, dark red skin eruption with some scales on her lower back (Picture 1), where local sensation was slightly disturbed. Neither nodular mass nor peripheral nerve thick-

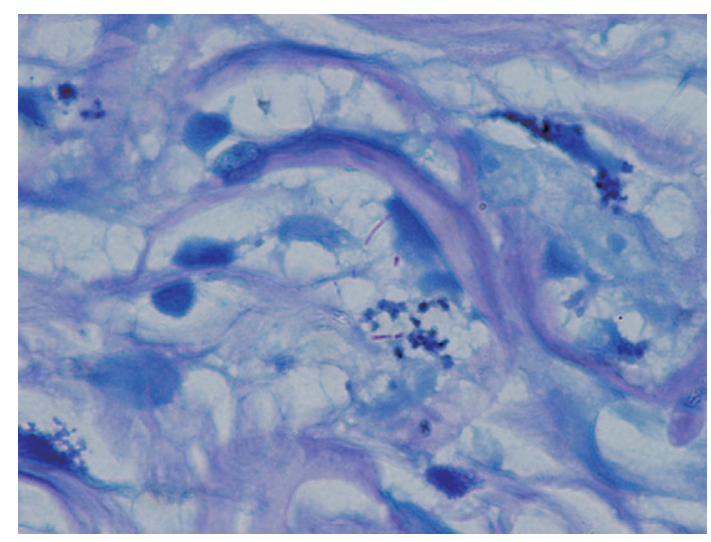

Picture 3.

ening was observed. Skin biopsy (Picture 2) revealed multiple epithelioid cell granuloma with Langhans-type giant cells in the whole dermis. No caseation necrosis was identified. These findings mimicked the histology of sarcoidosis. However, granulomatous involvement of peripheral nerves was evident and a few acid-fast bacilli were demonstrated by modified Ziehl-Neelsen stain (Fite method) (Picture 3). These findings led to a diagnosis of Hansen's disease (HD) of the tuberculoid type.

HD is a slowly progressive infection caused by Mycobacterium leprae (M. leprae), an acid-fast obligate intracellular organism. In Japan, HD is very rare and the number of new patients detected is reported to be 2-11 per year. Because of the histologic similarity (1), tuberculoid type HD may be misdiagnosed as cutaneous sarcoidosis. Identification of acid-fast bacilli can give pathognomonic hallmark and solve the differential diagnosis. However, because M. leprae is technically difficult to identify in routine paraffin sections, "the Fite method", a variant of Ziehl-Neelsen stain using oil xylene for deparaffinization, is the most commonly used. For lesions where bacilli are scanty, it is recommended that at least 6 sections should be examined before declaring

${ }^{1}$ Department of Pathology, Kyorin University School of Medicine, Japan and ${ }^{2}$ Department of Internal Medicine, Ofuna Chuo Hospital, Japan Received for publication April 11, 2011; Accepted for publication June 27, 2011

Correspondence to Dr. Katsuya Chinen, path.chinen@gmail.com 
them negative (2). Since HD is a curable disease, accurate diagnosis and effective therapy is very important. For its diagnosis, a high index of clinical suspicion is inevitable and a maximum effort to demonstrate $M$. leprae is necessary.

The authors state that they have no Conflict of Interest (COI).

\section{References}

1. Ball NJ, Kho GT, Martinka M. The histologic spectrum of cutaneous sarcoidosis: a study of twenty-eight cases. J Cutan Pathol 31: 160-168, 2004

2. Lowy L. Processing of biopsies for leprosy bacilli. J Med Lab Technol 13: 558-560, 1956.

\footnotetext{
(C) 2011 The Japanese Society of Internal Medicine http://www.naika.or.jp/imindex.html
} 